\title{
LIE DETECTION DURING THE INTERVIEW AND INTERROGATION PROCESS: A PSYCHOSOCIAL CRIMINAL APPROACH
}

\author{
Teodor MANEA \\ Lecturer Phd, Faculty of Law, " Titu Maiorescu " University, Romania \\ E-mail: teodor.manea@prof.utm.ro
}

\begin{abstract}
Lie detection is an important skill for any representative of the law involved in the interview and interrogation process. Unfortunately, there is much misinformation regarding what type of lie detection methods work. This paper is a review of the most important psychosocial criminal research on lie detection and identification the most effective methods. The method of lie detection by reading facial expressions (particularly micro-expressions) is with the conclusion that it is not an effective method. I propose that, considering what the scientific research has unveiled thus far, lie detection methods based on thorough information gathering and comparative analysis work best. Finally, I provide some specific recommendations on effective ways to apply such methods during the interview and interrogation process.
\end{abstract}

Key words: lie detection, deception, criminal law, social psychology, communication, micro-expressions, information gathering.

\section{Introduction}

The interview and interrogation process, whether conducted by lawyers, prosecutors, judges or police officers, is riddled with challenges. The person being interviewed or interrogated may not remember the facts correctly, they may have a hard time putting the facts into words, or they may simply refuse to cooperate. But one of the most intricate challenges involves the possibility that the person being interviewed or interrogated may have the intent of deceiving and may be lying. This is a realistic possibility whether this person is a suspect, a victim, a witness, or in some other way relevant to a legal investigation.

Lying in an everyday phenomenon, and not one specific to the legal investigation field. People lie every day for various reasons, from protecting others' feeling, to making themselves seem better than they really are, to 
manipulating and exploiting others. Likewise, wanting and seeking to detect lies is an everyday phenomenon. Highly valuing honesty, people have a profound abhorrence of being deceived and they are interested in being able to detect liars, cheaters, tricksters, in order to avoid them or, at a minimum, avoid being deceived by them. However, it is in the legal field where the act of lying has some of the weightiest implications. When suspects, victims, witnesses or other relevant parties in an investigation lie, they can put the entire investigation process off track by providing false leads, they can incur huge loses in terms of time, energy and money, and, above all, they can prevent the real culprit or culprits in a criminal deed from being identified and brought to justice.

Therefore, the ability to quickly and accurately detect lies is an important ability for any representative of the law who is involved in the interview and interrogation process. David E. Zulawski and colleagues, in their book, Practical Aspects of Interview and Interrogation, emphasize the value of accurate lie detection in criminal law, as well as the challenges related to the fact that "there is not a single behavior, verbal or physical, that accurately reflects whether an individual is being truthful or attempting to deceive. There is not even consistency within a single individual" (Zulawski and Wicklander 2001, p. 107).

Considering these facts, it is not surprising that over the last few decades, a rich multidisciplinary literature has emerged that deals with lie detection, targeting people who work in the criminal law and investigation field. The best knowledge during this time has come from well-done scientific studies at the intersection of law with other domains such as psychology, anthropology, communication, cognitive science, and social psychology. My objective in this paper is to reveal what the most important research concerning lie detection has discovered thus far, what intuitive ideas it has confirmed and what intuitive ideas it has disconfirmed. I will focus in particular on the research in social psychology, the field that studies the behaviors, thoughts and emotions of human beings as members of a much wider social environment, drawing practical implications to criminal law (Vaughan and Hogg 2013, p. 2). In other words, my perspective on lie detection will be psychosocial and criminal.

\section{Lie Detection and Micro-Expressions}

A common idea embraced by both laypeople and many professionals who work in the field of law-and-order, is that we can figure out whether a person is telling the truth or lying by analyzing their body language and facial expressions. A person who is lying is said to have particular, usually involuntary movements, gestures or facial expressions that act as tells and give away the lie. If we know what these tells are and we are able to spot them, we can successfully detect lies and separate the lies from the truth (Houston et al., 2012).

This idea has been popularized over the past few years by countless articles, books, such as the bestseller Spy the Lie, written by former CIA officers (Houston et al., 2012), as well as movies such as the TV series Lie to Me. In the very first scene of the first episode of Lie to Me, for instance, we see the main 
character, Cal Lightman, interrogating a captured member of a terrorist group that planted a bomb in a church in the U.S. state of Virginia. Lightman has an unusual interrogation technique though. He asks the terrorist questions about locations where the bomb might have been planted, but does not seek verbal answers (which the terrorist does not offer anyway). Instead, he looks very carefully at the non-verbal reactions of the terrorist at every question. Based on these, he correctly concludes that the bomb is at a church in the suburb of Lorton, which is where the anti-terrorism taskforce finds it and disarms it on time. In the next scene, taking place sometime later, Lightman is holding a presentation in front of agents from various governmental agencies, showing them the video of this interrogation and explaining with its aid how he realized which was the right location to look for the bomb by reading the terrorist's nonverbal communication, particularly his facial expressions (Lie to Me TV Series, Season 1, Episode 1, January 2009, min. 1-4).

Lightman describes his lie detection technique as being based on reading what he calls "micro-expressions", meaning very fast and very short changes in non-verbal communication, lasting less than a fifth of a second, that reflect a certain emotion, emotion which can further be used to deduce if what has been said is true or false (Lie to Me TV Series, Season 1, Episode 1, January 2009, min. 1-4). Interestingly enough, the term "micro-expression" is actually used in the real world in research on emotions and communication, with the meaning described by Lightman. The idea of micro-expressions goes all the way back to Charles Darwin, the renowned formulator of the theory of evolution by natural selection. Darwin believed that, because emotions involve lots of involuntary gestures and muscle movements, we cannot totally inhibit their external expression. Even when we try to hide an emotion, it will still leak out in subtle ways through our gestures and facial expressions. These gestures and facial expressions were later titled "micro-expressions" by researchers on human non-verbal communication such as Paul Ekman (Ekman 2009, pp. 3449$3451)$.

As the theory goes, since emotions are involuntarily expressed via micro-expressions, these cues can help us find out whether or not a person is lying. For instance, when a person is lying, they will almost always experience some anxiety, discomfort or guilt. This feeling will in some subtle way be conveyed non-verbally, and if we are vigilant or well-trained, we can catch that non-verbal expression, deduce the underlying emotion, and thus realize that a lie has been communicated (Navarro and Karlins 2008, 209-213). This all sounds very good, in theory. But what does the scientific research say on this very important subject? Can we really detect lies by reading body language and facial expressions?

\section{What the Research Says}

If micro-expressions are real, then our true emotions are expressed in subtle ways, and people can detect them if they pay attention. If this were the case, then we should expect people in general to be quite good at spotting liars when they are paying attention. Unfortunately, the research, does not support 
this hypothesis. Quite the contrary, most of the research on lie detection via reading non-verbal cues suggests that we are quite bad at it.

In a first study worth mentioning, conducted by psychologists Stephen Porter and Leanne ten Brinke from the University of British Columbia, some subjects were asked to try to detect the emotions of other subjects who sometimes would let their emotions manifest freely, and other times would try to mask them. According to the authors of the study, "untrained observers performed only slightly above chance at detecting deception", which is quite disappointing given the theory about reading micro-expressions presented above. Micro-expressions were present in an inconsistent manner when the subjects of this study who were supposed to try and mask their emotions did so. "Micro-expressions were exhibited by $21.95 \%$ of participants in $2 \%$ of all expressions," the study authors tell us. Some form of subtle emotional expression did exist in all these subjects, though when attempting to mask emotions the expressions lasted too long to be qualified as micro-expressions. They were probably also weak in intensity, since subjects who tried to detect deception did not notice them very often (Porter and Brinke 2008, 508-514).

In discussing the results of this study, psychologist Nicholas Epley, points out that not only these micro-expressions, which supposedly reveal lies, were few and far between, but they also did not seem to consistently indicate lying. Of the 697 expressions that were seen by evaluator-subjects in this study, only 14 included micro-expressions, and in half the cases in which they appeared, the person with the respective expressions was indeed lying, while in half the cases he or she was telling the truth. This leads us to the natural conclusion that, in Epley's words, "these exceptionally rare micro-expressions seem just as likely to mislead you about the mind of another as they are to reveal it to you (Epley 2014, 165-167)."

Other studies demonstrate that we are bad at detecting lies even when the other person tells very big and risky lies. Stephen Porter and Leanne ten Brinke emphasize this in a review paper summarizing the findings of some of the best research in the area of high-stake lies. They claim that, "although highstakes lies subjectively may be harder for liars to tell, their behavioural manifestations are neither obvious nor necessarily simply magnified versions of those of lower stakes lies (Porter and Brinke 2010, 57-75)." The result is that high stake lies are just about as hard to detect as low stake ones. The authors also provide some criticism of polygraph testing, pointing out that "the control question test (CQT) suffers from a high false positive rate, often classifying honest suspects as being deceptive" (Porter and Brinke 2010, 57-75). This is likely due to the high level of anxiety some subjects experience when taking a polygraph test, which can be quite easily misinterpreted as intent to deceive.

\section{What About Trained Lie-Detectors?}

Of course, many people may claim that the average person is bad at detecting lies via micro-expressions, as these studies show, but a person trained in lie detection will surely fare much better. Unfortunately, the research does not provide encouraging results in support of this idea either. In fact, the studies 
indicate quite clearly that people with experience and training in lie detection are either no better at spotting lies via non-verbal cues than the average person, or only slightly better than the average person.

Psychologists Michael G. Aamodt and Heather Custer conducted a meta-analysis of individual differences in deception detection, on the basis of 108 separate studies. They found that "professional lie catchers such as police officers, detectives, judges, and psychologists ... were no more accurate at detecting deception than were students and other citizens" (Aamodt and Custer 2006, 6-11). This is an important finding and it should raise a warning signal regarding being too confident in one's lie detection abilities, even if one is an experienced worker in a profession that involves regularly trying to spot lies.

Another relevant set of data in this area comes from the research of psychologist Kang Lee, who focused mainly on child development. He points out how children learn from an early age how to lie effectively, by mimicking, while lying, the body language, facial expressions and verbal patterns of a person who is telling the truth. By the age of five, they get so good at it that adults are generally not able to tell whether a 5-year-old child is being honest or deceitful at a rate any higher than pure chance. Lee's experiments, and those of his colleagues, show quite clearly, and perhaps shockingly, that the behaviors of children who lie "cannot be distinguished accurately by naive adults ... including parents, child protection lawyers, social workers, police, customs officers, and judges" (Lee 2013, pp. 91-96).

In his 2016 TED Talk, which received several million views and many positive reviews, Lee shows the audience a graph based on his experiments, about the ability of various categories of adults to detect the lies of children via non-verbal cues. As the lines for each adult category and their lie-detection performance appear on the graph in a preset order, they all position themselves around the $50 \%$ mark, which signifies a lie-detection performance equal to the level of chance or slightly above. Undergraduates, law students, social workers, child protection lawyers, judges, customs officers, police officers, other's parents and one's own parent, they all appear to be quite bad at spotting liars (Lee 2016, minutes 6-9). This certainly does not bode well for the idea that people can get significantly better at lie detection via non-verbal cues by practice and training.

Sadly, leaders of organizations and institutions that are interested in lie detection are frequently not aware of this important research, and they are eager to pour large sums of money in training programs for their employees focused on teaching them to catch and interpret micro-expressions in order to detect liars. One such very large-scale program is called SPOT (Screening of Passengers by Observation Techniques). It was developed and run by the Transportation Security Administration (TSA), an agency of the U.S. Department of Homeland Security, and cost 900 million dollars in its first six years of implementation (Halsey III 2021). But its results were underwhelming. According to psychologist Nicholas Epley, who studied the effectiveness of the SPOT program, "less than 1 percent of those identified by SPOT officers [for additional questioning] were actually arrested for a criminal offense, and 99 
percent were needlessly detained." Among those arrested, 40 percent were arrested for being illegal aliens. Not a single terrorist was identified though (Epley 2014, pp, 165-167).

In conclusion, we are essentially all bad at detecting lies via non-verbal communication cues. We are even bad at detecting high-stakes lies, as well as lies told be five-year-olds. And those with training and experience in lie detection either fare no better than the rest of us, or, at times, fare only slightly better. Besides how disappointing or surprising these findings can be, they also beg the question: why is this the case? Should we not, as a profoundly social species with a large brain, be better at detecting lies?

\section{The Evolution of Human Lie Detection Skills}

According to evolutionary theory, living organisms change and adapt over time as a result of genetic mutations, which are random, and natural selection, which is non-random. This applies to humans as well, and to those psychological needs, character traits, social abilities and cognitive skills we possess that have a genetic, inherited and inheritable component. They have evolved over tens and hundreds of thousands of years, because of their adaptive value for our survival, reproduction and thriving (Mayr 2001, pp. 91-162).

Evolutionary psychologists and anthropologists have speculated for a long time that, given the practical importance of the ability to detect liars and cheaters, humans should have, over time, evolved advanced lie detection mechanisms. Reading body language and facial cues seems like a potentially good mechanism for that. As French anthropologist Pascal Boyer says: "Deception may be adaptive, if you can exploit others, but then it becomes adaptive for others to develop the symmetrical weapon, the ability to see through deception" (Boyer 2018, 65). And so, he claims there is a continual evolutionary arms race in which, as some people get better at lying, other people get better at detecting lies. Still, even if we have some lie detection abilities as a species and it makes evolutionary sense for us to have them, reading microexpressions or other similar non-verbal cues does not work. There must be something else that enables us to detect lies.

That something else may begin to reveal itself when we consider the kind of environment in which we human beings have lived for the vast majority of our existence as a species. For over 200,000 years, we humans lived as nomadic hunter-gatherers, organized into small bands and tribes where everybody knew everybody else and they interacted regularly. It was merely 10,000 years ago that we began to develop agriculture and animal husbandry, settle down, grow in population, raise towns and cities, (Harari 2015, pp. 1-2).

As cognitive scientist Hugo Mercier indicates, in such close-knit tribal societies, there was rich information available about any member of the tribe. Thus, we "had plenty of information to recognize aligned or misaligned incentives; to spot overconfident, unreliable, deceitful individuals; and to adjust accordingly how we value their commitment" (Mercier 2020, pp. 92-93). This means that no person could lie often, even big lies, without eventually being found out. When a tribe member would lie to us, we would soon enough get 
some new piece of information that would contradict what this person said and would reveal their lie. Furthermore, since information circulates easily in tribes, once a liar has been exposed by one person, the entire tribe would find out. As psychologist Jesse Bering poignantly describes the situation: "Imagine the very worst thing you've ever done- the most vile, scandalous, and vulgar. Now imagine all the details of this incident tattooed on your forehead. This scenario is much like what our ancestors would have encountered if their impulsive, hedonistic, and self-centered drives weren't kept in check" (Bering 2012, 186). These drives would also include lying.

Author Timothy Levine (whose work we will discuss in more detail shortly) adds another valuable idea. He claims that the evolution of advanced skills for lie detection by reading facial cues would not have been necessary for our ancestors because they had another impactful way of minimizing lies, especially very harmful ones, deterrence. All the cultures studied by anthropologist have some sort of social or legal norms in place that punish those who lie and cheat, in some proportion to the size of the lie or the harm done (Levine 2014, pp. 378-392). Frequent liars can incur costly punishment, including exclusion from the social group altogether. In the wild and dangerous world that our hunter-gatherer ancestors lived, this exclusion (which would be from the entire clan or tribe) is in no way similar to being kicked out of a group of friends in our modern world where you can find another group to befriend. The ultimate consequences for a compulsive liar living some 50,000 years ago, left to fend for himself on the savannah or in the jungle, could be dire.

In conclusion, it is clear that the kind of a hunter-gatherer social system in which our species lived for most of its existence, in which social information is abundant, spreading easily from person to person, and punishments for liars being costly, there is no incentive for the forces of biological evolution to give us advanced abilities to detect lies by reading non-verbal cues. When someone would lie, the true facts would surface and spread on their own soon enough, by the mere act of people casually talking and interacting with each other, within the tribe and sometimes with outsiders.

\section{Information Verification}

This brief discussion on evolution reveals a lie detection strategy that truly seems to work, which entails information verification, acquiring information on the same topic or issue from multiple sources and with rich details, which can lead to the discovery of conflicting data. (By "information verification" and "acquiring information" I am not referring to the means of obtaining information via non-verbal cues, only through other means). At that point we need not resolve the conflict, usually accomplished by gathering even more data and assessing the credibility of each information source. This process can eventually reveal false information that was deliberately presented with the knowledge that is false, which is another way of saying: it can reveal lies. Of course, in the modern world, much more information is available than in huntergatherer times, but much of it is also hard to access. This should not be a 
deterrent from trying though, especially when we have the authority of being representatives of the law.

Communications researcher Timothy R. Levine, in his Truth-Default Theory (TDT) explored information verification. According to this theory, we human beings are naturally inclined to assume that when someone tells us something, they are being honest. To start off with the opposite assumption and need to fact-check every sentence that is being uttered would make effective communication nearly impossible. Thus, an assumption of honesty is necessary for communication between any two or more individuals to function. Another part of the theory states, in line with the research discussed above, that to detect deception by the demeanor of the liar is rarely possible. "Honest-looking and deceptive-looking communication performances are largely independent of actual honesty and deceit for most people, and hence usually do not provide diagnostically useful information", says Levine (Levine 2014, 378-392). This disconnect between honesty and body language may seem odd, but the research, as discussed already, bears this out. And evolutionary theory does provide a reasonable explanation for why this disconnect does exist.

Truth-Default Theory claims that there are, nevertheless, ways by which we can reliably detect lies. There are particular triggers that can get a person to abandon their default state of believing what they hear and, instead, begin to doubt it. When enough of these triggers get activated, and enough doubt builds up, the claims of the interlocutor are rejected as lies. "We have a sort of cognitive and emotional internal alarm system that moves us, based on certain crucial clues, from the assumption that our interlocutor is being honest, to suspicion, to distrust, to certainty that we are being told lies. These triggers include: (a) a projected motive for deception, (b) behavioral displays associated with dishonest demeanor, (c) a lack of coherence in message content, (d) a lack of correspondence between communication content and some knowledge of reality, or (e) information from a third-party warning of potential deception" (Levine 2014, 378-392).

As we can see, the first trigger has to do with the motivations of the speaker, which can sometimes incentivize them to lie rather than to tell the truth. It is always good to understand a person's interests, because we can employ that information to establish, to some degree, their level of trustworthiness. The second trigger is about behavioral displays, but here we are talking about overt behaviors that cause suspicion, such as stating something as factual while barely containing laughter. Such behavior is very rare, and is something quite different from micro-expressions. The other three triggers all have to do with acquiring information (by ways other than reading non-verbal cues) that invalidates an initial claim and may potentially expose it as a lie. This information may be provided by the liar himself, who is unable to keep track of his lies and their implications, and thus spins an incoherent story. It can also come from the mismatch between what we just heard and what we already know as part of our background knowledge. This is where a welleducated, knowledgeable person has an advantage. Finally, information can come from other people with relevant knowledge (such as witnesses), who are 
very important sources of information in a criminal investigation, especially if their trustworthiness had already been proven. As Levine puts it, "the path to improved human lie detection involves listening to what is said, rather than to how it is said" (Levine 2019, xi).

The research of psychologist Paul Ekman and his colleagues indicates there are seven basic human emotions, which can be identified by people in virtually all cultures based on facial expressions: happiness, fear, anger, sadness, surprise, disgust and interest (Ekman, Friesen \& Ellsworth 1972, pp, 64-65). However, when a person tells a lie, they may not experience any of these basic emotions, or they may experience a subtle mix of them at a low intensity, or they may find it fairly easy to repress them. So, it is hard to catch non-verbal hints of deception (provided they even exist) and then interpret them correctly. On the other hand, disconfirming information can come from a variety of sources in order to prove a claim as false and expose a lie.

Of course, listening and collecting information that may reveal a lie are time-consuming tasks, which do not sound as appealing as reading microexpressions and detecting lies within seconds. We no longer live in the closeknit tribal societies we lived in tens of thousands of years ago, in which we only knew several dozen people and deceitful information would be revealed quickly and easily. We often have to work hard for the truth to come out. Nevertheless, the evidence strongly suggests that information verification is what truly works in lie detection, so as hard as it may be at times, this is what good representatives of the law should rely on.

\section{Making the Information Flow}

Since discovering conflicting information is a proven way to detect lies, it stands to reason that an effective way for a lawyer, prosecutor, judge or police officer to spot lies is to gather as much relevant information as possible related to the issue being investigated, trusting that if lies have been told, mismatches between pieces of acquired information will eventually emerge and reveal the deception. As mentioned above, Timothy Levine has discovered three different informational triggers that can suggest a lie has been told (Levine 2014, pp. 378-392). Taking these triggers into consideration, we can make two practical recommendations related to the interview and interrogation process that representatives of the law can employ for better lie detection.

The first recommendation is for representatives of the law to ask as many questions as possible and obtain details from any person they are interviewing or interrogating. Lies usually need other lies supporting them in order to build a coherent and detailed story. If I falsely tell someone that I spent the entire previous weekend hiking on my own and they ask for details, I will probably also have to talk about how I got there, what paths I used to climb, what climbing equipment I used, where I ate, or where I slept. Thus, I need to weave a whole system of lies to sustain the initial lie, and then I have to remember all these lies in the system accurately, so I do not contradict myself at any point. 
This is a weakness that can be leveraged by the person running an interrogation or interview. By asking many questions, trying to get a thorough understanding of the situation at hand, they will force the person doing the answering, if they are lying, to weave an ever-growing web of lies. Eventually, they may forget some of the lies from this web, and when they restate some of the invented facts, they will say a new lie that contradicts an old one. In the example above, I may first say I stayed at a certain hotel, and later at another hotel. This reflects the usefulness of not only asking for many details, but also asking the same questions several times. It is in the repetition of various supposed facts where liars often slip up and thus, reveal their lies. Furthermore, by asking lots of questions, a representative of the law may eventually learn something that they know, based on their background knowledge, is not true. Using the example above again, maybe I will say I stayed at hotel X during my hiking trip, but the interviewer knows for a fact that hotel is undergoing renovation and is closed. Or I may say it took me two hours to drive to the hiking destination, but the interviewer knows for a fact that trip takes less than an hour, driving, on a day with normal weather. This illustrates unambiguously, not only the importance of asking lots of questions, but also of having good background knowledge. As a representative of the law, it is beneficial to know lots of things and have lots of information regarding the things going on around you. Knowledge is power in more ways than one.

The second practical recommendation for representatives of the law is to interview as many people as possible regarding the same incident, and get the story on the incident from as many angles as possible. Various witnesses of a crime for instance, may be able to complement one another in the information they share, since not all people who witness an event observe and remember the same things. In addition, contradictions between witnesses can reveal lies. Representatives of the law have to be careful in how they interpret such contradictions though. Sometimes a witness may have simply misheard something or misremembered something, but they are not intentionally deceiving. Psychologists have known for decades that human memory relies a lot of reconstruction, of filling in the gaps, and this can easily make us recollect events we witnessed in a way that is slightly different from the way they actually happened (Shaw 2017, p. 8). Also, if two people share different stories on the same issue, while it could be a sign that one of them is lying, many other aspects need to be considered in order to correctly determine which person is the liar. The discovery of a contradiction is just the beginning of a longer process with the goal of figuring out the precise meaning of said contradiction. Nevertheless, patience, curiosity and attention to details will help the investigator to successfully navigate this process and reveal the truth.

\section{Lies and Cognitive Load}

Besides gathering information in order to discover incoherencies, there is another strategy for detecting lies that can work well. This strategy revolves around the fact that coming up with lies is a creative process, which frequently involves more mental effort than remembering something. As forensic 
specialists Nathan J. Gordon and William L. Fleisher state, when lying, "more cognitive energy has to be allocated to creative or control processes. Therefore, the description of the alleged event might result in a poorer outcome, fewer details, and a less vivid picture than reports about experienced events" (Gordon and Fleischer 2011, 59-60). Not only will a lie lack the vividness and details of a real event, but the cognitive effort involved in creating it will also take up a noticeable amount of time, usually longer than remembering the truth, especially in the case of a recent event.

This leads us to a potentially highly effective method for revealing lies: asking questions that one can answer swiftly if answering from memory, but much slower if they are then-and-there inventing the answer in their own mind. In psychological terms, this means increasing a person's cognitive load, the amount of information they have to consciously process, which alters the results that will be produced or the time it takes to produce them.

Psychologists and neuroscientists have been experimenting on the manipulation of cognitive load in a variety of interesting ways. For example, neuroscientist Joshua Greene has put participants under cognitive load by asking them to perform an attention-demanding task, while also presenting them a moral problem and asking them if the parties involved in the situation acted morally or immorally. He and his colleagues noticed that when a person is under cognitive load, they are more inclined to intuitive answers to moral problems, while when they are not under cognitive load, they are more likely to give a utilitarian answer (Greene 2013, pp. 126-128). This makes sense, since utilitarian thinking requires considerably more mental effort than using our intuitions, and there is simply not enough mental bandwidth to think in a utilitarian manner when one is put under considerable cognitive load.

The manipulation of cognitive load can be used beyond testing moral thinking, in the field of lie detection, by asking questions that create significant cognitive load if the answer is a lie, but not if the answer is true. This approach has been studied experimentally and the studies so far have yielded good results. In a study conducted by Aldert Vrij and colleagues, "pairs of liars and truth tellers were interviewed individually about having had lunch together at a restaurant ... While the truth tellers did have lunch together, the liars did not but were instructed to pretend that they had". The interviewers included unanticipated questions in the interview. While the liars performed just as well as the truth tellers when answering simple, predictable questions, they performed much more poorly when answering unpredictable questions, taking much more time to do so. As a consequence, "based on the responses to the unanticipated questions, up to $80 \%$ of pairs of liars and truth tellers were correctly classified (Vrij et. al, 2011)."

This suggests that asking unanticipated questions is an effective technique to spot liars, since it takes more time to answer them when one is lying than when one is telling the truth. What qualifies as an unanticipated question will vary depending on the person being questioned. One person may invent a lie about having gone hiking the previous weekend and think of pretty much any question they might receive regarding the trip, and come up with 
answers for all of them ahead of being interviewed. Another person may barely anticipate a couple of questions, and be put on the spot when somebody asks them about something else regarding their trip. It is important for the representative of the law to be able to come up with questions the interviewee did not anticipate or did not have time to prepare for in advance.

\section{Conclusions}

The past few decades of research at the intersection of psychology, sociology, communication and criminal law have produced some interesting and useful findings for any lawyer, prosecutor, judge or police officer conducting interviews or interrogations. On one hand, the research has largely debunked the commonly held idea that we can detect lies by reading the speaker's body language and facial expressions. Although this idea may seem intuitively correct, the research simply does not support it, and it is time we retire it from the legal investigation bag of tools. On the other hand, this research has shown us that information verification, by which I mean collecting and comparing significant quantities of germane information regarding the situation under scrutiny, is an effective lie detection method. The glass is either half empty or half full, depend on which part of it we want to look at.

This line of inquiry suggests that rather than seeking to train police officers, detectives, lawyers, judges and prosecutors in the fuzzy art of lie detection via reading facial expressions, the criminal and legal investigation domain would benefit much more from training them to use effective questioning and information assessment techniques during the interview and interrogation process, in order to reveal inconsistencies that reflect lies. More funds towards training such personnel should go in the direction of teaching them evidence-based lie detection techniques, rather than speculative methods for "reading people" with questionable scientific support.

Beyond this, we are eager to see even more quality research on lie detection being performed in the near future by scientists around the world, particularly with a collaborative multidisciplinary approach, which will hopefully produce even more practical know-how for improving lie detection abilities. There is certainly much more for us to learn in this area, and the resulting knowledge has quite board applications, from the criminal and legal investigation field which interests us in particular, to media and communication, to politics, to social activism, to everyday social exchanges between regular people seeking to have more honest and more authentic interpersonal relationships. 


\section{REFERENCES}

Aamodt, M. G. and Custer, H. 2006. "Who Can Best Catch a Liar?: A MetaAnalysis of Individual Differences in Detecting Deception". Forensic Examiner 15 (1): 6-11.

Bering, J. 2011. The Belief Instinct: The Psychology of Souls, Destiny, and the Meaning of Life. New York: W. W. Norton \& Company.

Boyer, P. 2018. Minds Make Societies: How Cognition Explains the World Humans Create. New Haven: Yale University Press.

Ekman, P. Friesen, W.F. and Ellsworth, P.C. 1972. Emotion in the Human Face: Guidelines for Research and an Integration of Findings. New York: Pergamon Press Inc.

Ekman, P. 2009. "Darwin's contributions to our understanding of emotional expressions". Philosophical Transactions 364 (1535): 3449-3451. doi.org/10.1098/rstb.2009.0189.

Epley, N. 2014. Mindwise: Why We Misunderstand What Others Think, Believe, Feel, and Want. New York: Knopf.

Gordon, N. J. and Fleisher, W.L. 2011. Effective Interviewing and Interrogation Techniques, Third Edition. New York: Academic Press.

Greene, J. 2013. Moral Tribes: Emotion, Reason, and the Gap Between Us and Them. New York: Penguin Press.

Halsey, A. III. 2021. "House member questions \$900 million TSA 'SPOT' screening program". The Washington Post.

www.washingtonpost.com/local/trafficandcommuting/house-memberquestions-900-million-tsa-spot-screeningprogram/2013/11/14/ad194cfe-4d5c-11e3-be6bd3d28122e6d4_story.html.

Harari, Y. N. 2015. Sapiens: A Brief History of Humankind. New York: Harper. Houston, P., Floyd, M., Carnicero, S. and Tennant, D. 2012. Spy the Lie: Former CIA Officers Teach You How to Detect Deception. New York: St. Martin's Press.

Lee, K. 2013. "Little Liars: Development of Verbal Deception in Children", Child Development Perspectives 7 (1): 91-96.

doi.org/10.1111/cdep.12023.

Lee, K. 2021. "Can you really tell if a kid is lying?", TED 2016, accessed

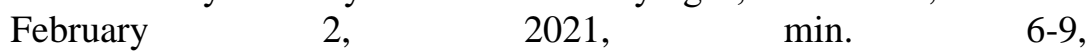
www.ted.com/talks/kang_lee_can_you_really_tell_if_a_kid_is_lying.

Levine, T. R. 2014. "Truth-Default Theory (TDT): A Theory of Human Deception and Deception Detection”. Journal of Language and Social Psychology $33 \quad$ (4): http://doi.org/10.1177/0261927X14535916.

Levine, T. R. 2019. Duped: Truth-Default Theory and the Social Science of Lying and Deception. Tuscaloosa: University Alabama Press.

Mayr, E. 2002. What Evolution Is. London: Phoenix.

Mercier, H. 2020. Not Born Yesterday: The Science of Who We Trust and What We Believe. Princeton: Princeton University Press. 
Navarro, J. and Karlins, M. 2008. What Every BODY is Saying: An Ex-FBI Agent's Guide to Speed-Reading People. New York: HarperCollins.

Porter, S. and Brinke, O.L. 2008. "Reading Between the Lies: Identifying Concealed and Falsified Emotions in Universal Facial Expressions", Psychological Science 19 (5): 508-514. doi.org/10.1111/j.14679280.2008.02116.x.

Porter, S. and Brinke, L. 2010. "The truth about lies: What works in detecting high-stakes deception?”. Legal and Criminal Psychology 15 (1): 5775. doi.org/10.1348/135532509X433151.

Shaw, J. 2017. The Memory Illusion: Remembering, Forgetting, and the Science of False Memory. London: Random House Books.

Vaughan, G.M. and Hogg, M.A. 2013. Social Psychology, Seventh Edition. London: Pearson Education Ltd.

Vrij, A., Granhag, P.A., Mann, S. and Leal, L. 2011. "Outsmarting the Liars: Toward a Cognitive Lie Detection Approach". Current Directions in Psychological Science $20 \quad$ (1):28-32. http://doi.org/10.1177/0963721410391245.

Zulawski, D. E. and Wicklander, D. E. 2001. Practical Aspects of Interview and Interrogation, Second Edition. New York: CRC Press. 